\title{
History of Writing and Record Keeping
}

\author{
by Rochelle Forrester \\ Copyright () 2016 Rochelle Forrester \\ All Rights Reserved \\ The moral right of the author has been asserted
}

\begin{abstract}
Anyone may reproduce all or any part of this paper without the permission of the author so long as a full acknowledgement of the source of the reproduced material is made.

e-mail rochelle.fo@xtra.co.nz
\end{abstract}

Second Edition

Published 31 October 2016

This paper was written in order to examine the order of invention of the various writing systems developed by humans. It is part of my efforts to put the study of social and cultural history and social change on a scientific basis capable of rational analysis and understanding. This has resulted in a hard copy book How Change Happens: A Theory of Philosophy of History, Social Change and Cultural Evolution and a number of websites such as http://homepages.paradise.net.nz/rochelle.f/, Sense Perception and Reality and How Change Happens and How Change Happens Rochelle Forrester's Social Change, Cultural Evolution and Philosophy of History website. There are also papers on Academia.edu, Figshare, Mendeley, Vixra and Social Science Research Network websites and other papers on Google docs such as Sense Perception and Reality, How Change Happens, The History of Medicine, The Discovery of the Atomic World and the Constituents of Matter and on Guttman Scale $\underline{\text { Analysis and its use to explain Cultural Evolution and Social Change and on Issuu and Scribd. }}$

\begin{abstract}
The ultimate cause of much historical, social and cultural change is the gradual accumulation of human knowledge of the environment. Human beings use the materials in their environment to meet their needs and increased human knowledge of the environment enables human needs to be met in a more efficient manner. The human environment includes the human being itself and the human ability to communicate by means of language and to make symbolic representations of the sounds produced by language, allowed the development of writing. Writing developed over time in a necessary and inevitable manner from logographic, to syllabic, to alphabetical systems. This development from simpler word based writing to more complex syllable based systems and then even more complex sound based writing systems was a logical progression from, simple less useful systems, to more complex, but more useful systems. This is an example of how the simplest knowledge is acquired first and more complex knowledge is acquired later. The order of discovery determines the course of human social and cultural history as knowledge of new and more efficient means of meeting human needs, results in new technology, which results in the development of new social and ideological systems. This means human social and cultural history, has to follow a particular course, a course that is determined by the structure of the human environment.
\end{abstract}


Writing was first invented by the Sumerians in ancient Mesopotamia before 3,000 BCE. It was also independently invented in Meso-America before $600 \mathrm{BCE}$ and probably independently invented in China before 1,300 BCE. It may have been independently invented in Egypt around 3,000 BCE although given the geographical proximity between Egypt and Mesopotamia the Egyptians may have learnt writing from the Sumerians.

There are three basic types of writing systems. The written signs used by the writing system could represent either, a whole word, a syllable or an individual sound. Where the written sign represents a word the system is known as logographic as it uses logograms which are written signs that represent a word. The earliest writing systems such as the Sumerian cuneiform, Egyptian hieroglyphics and Mayan glyphs are predominantly logographic as are modern Chinese and Japanese writing systems. Where the written sign represents a syllable the writing system is known as syllabic. Syllabic writing systems were more common in the ancient world than they are today. The Linear A and B writing systems of Minoan Crete and Mycenaean Greece are syllabic. The most common writing systems today are alphabetical. These involve the written sign (a letter) representing a single sound (known as a phoneme). The earliest known alphabetical systems were developed by speakers of Semitic languages around $1700 \mathrm{BCE}$ in the area of modern day Israel and Palestine. All written languages predominately use one or other of the above systems. They may however partly use the other systems. No written language is purely alphabetic, syllabic or logographic but may use elements from any or all systems.

In order for there to be writing, three criteria must be met:

-the writing must consist of artificial graphical marks on a durable surface -the purpose of the marks must be to communicate something -the purpose must be achieved due to a conventional relationship between marks and language

Such fully developed writing only emerged after development from simpler systems. Talley sticks with notches on them to represent a number of sheep or to record a debt have been used in the past. Knotted strings have been used as a form of record keeping particularly in the area around the Pacific Rim. They reached their greatest development with the Inca quipus where they were used to record payment of tribute and to record commercial transactions. A specially trained group of quipu makers and readers managed the whole system. The use of pictures for the purpose of communication was used by native Americans and by the Ashanti and Ewe people in Africa. Pictures can show qualities and characteristics which cannot be shown by tally sticks and knot records. They do not however amount to writing as they do not bear a conventional relationship to language. Even so, the Gelb dictum (from its originator Ignace Gelb), that "At the basis of all writing stands the picture" has been widely accepted.

An alternative idea was that a system by which tokens, which represented objects like sheep, were placed in containers and the containers were marked on the outside indicating the number and type of tokens within the container, gave rise to writing in Mesopotamia. The marks on the outside of the container were a direct symbolic representation of the tokens inside the container and an indirect symbolic representation of the object the token represented. The marks on the outside of the containers were graphically identical to some of the earliest pictograms used in Sumerian cuneiform. However cuneiform has approximately 1,500 signs and the marks on the outside of the containers can only explain the origins of a few of those signs.

The first written language was the Sumerian cuneiform. Writing mainly consisted of records of numbers of sheep, goats and cattle and quantities of grain. Eventually clay tablets were used as a writing surface and were marked with a reed stylus to produce the writing. Thousands of such clay tablets have been found in the Sumerian city of Uruk. The earliest Sumerian writing consists of pictures of the objects mentioned such as sheep or cattle. Eventually the pictures became more abstract and were to consist of straight lines that looked like wedges.

The earliest cuneiform was an accounting system consisting of pictograms representing commodities such as sheep and a number. The clay tablets found might for example simply state "ten sheep". Such writing obviously has its limitations and would not be regarded as a complete writing system. A complete writing system only developed with the process of phonetization. This occurs when the symbol ceases to represent an object and begins to represent a spoken sound, which in early 
cuneiform would be a word. This process was assisted when the symbols, which initially looked very like the object they represented, gradually became more abstract and less clearly related to an object. However, while the symbol became more closely connected to words, it was words dealing with objects, such as sheep, bird or pot. It was still not possible to write more abstract ideas such as father, running, speech or foreigner.

The solution to this problem was known as the rebus principle. Words with the same or similar pronunciation to an abstract word could be used to represent the abstract word. The sign for eye could be used to represent the word "I". The sign for deer could represent the word "dear". Which word is referred to by the picture is decided by an additional sign. Pictographs which originally represented a word began to represent the sound of the word. The rebus principle is used to represent abstract words in all word writing systems in Sumer, Egypt, China, and in the Aztec and Mayan writing in central America.

The Rebus principle led to cuneiform becoming a form of logo-syllabic writing consisting of both logograms and syllabic writing. The effect of the change from logographic to logo-syllabic writing was substantial. Logographic writing cannot produce normal prose and is restricted to nouns, numbers, names and adjectives. The vast majority of early Sumerian writing consisted of bureaucratic records of products received or products distributed. Only when syllabic writing was introduced into cuneiform did it become possible to write prose such as myths and royal propaganda.

The next major development in writing in the old world was the development of the alphabet. The alphabet was developed out of Egyptian hieroglyphs which contained 24 signs for 24 Egyptian consonants. About 1700 BCE Semites who knew Egyptian hieroglyphs began making certain changes in their writing system. They put the letters in a particular sequence and gave them simple names to assist learning and ease of memory. They also dropped the logograms and other signs used in hieroglyphs and just kept the Egyptian consonants and restricted the signs to those for individual consonants. Finally they introduced vowels into their alphabet. Alphabets were soon to spread over most of the world as they provide both flexibility and simplicity for a writing system.

Writing also developed independently in Meso-America about 650 BCE. The earliest MesoAmerican writing seems to be logographic writing produced by the Olmecs. Later the Maya developed a writing system that was partly logographic and partly syllabic. There are broad similarities between the Maya writing and the logo-syllabic writing systems used in the old world. Mayan syllabic signs are pictographs of objects whose pronunciation begins with that syllable which is the same system used in early Semitic alphabets. The rebus principle is used for logograms for abstract words as it is used in Sumerian cuneiform. Mayan syllabic signs were commonly signs for syllables of a single constant and one vowel as in the Linear B writing system of Mycenaean Greece. Similar problems which emerged while developing a writing system were solved in similar ways in both the old world and the new world.

Writing developed both in the old and the new worlds as a movement from the simple to the complex in the form of increasing abstraction. The simplest way to make a record of something is to draw a picture of it, so that the earliest writing was logographic. However the limitations of logographic writing were to result in the development of syllabic writing to allow for the writing of prose and for a reduction in the number of signs used. The most difficult system to invent due to its high level of abstraction was the alphabet system which was why it was the last system invented in the old world and why it had not been invented in the new world by the time of the Spanish conquest. Florian Coulmas in The Writing Systems of the World states:

"The general tendency of development is roughly from pictogram to alphabet via word writing first and then syllabic writing." (Coulmas, Florian (1989) The Writing Systems of the World, Basil Blackwell, Oxford 34).

Later he states:

"Syllables are clearly more abstract and more difficult to conceive of than words, and accordingly syllabic writing appears historically later than word writing." (Ibid, 41).

Still later he states: 
"The alphabet is the logical conclusion of a development of ever increasing abstraction. As its units are minute and highly abstract it is in principle, universally applicable. ... It is a generally accepted view that the alphabet is the teleological goal of the history of writing." (Ibid. 47).

The move from logographic, to syllabic, to alphabetical writing was a move from the easiest form of writing to invent to the most difficult form of writing to invent. The increasing difficulty is caused by the increasing level of abstraction with the move from logographic, to syllabic and then to alphabetic writing. However as the level of abstraction increases, the ease of use of the writing system increases. This is because the number of signs used falls, with logographic systems typically employing thousands of signs, syllabic systems anywhere from 50 to many hundreds and an alphabetic system like the Roman alphabet, 26 signs. This is because the number of words in a language always exceeds the number of syllables and the number of syllables will normally exceed the number of phoneme, upon which alphabetic writing is based.

If writing, or a similar record keeping system like the Inca quiqu, had not been invented, then it is doubtful whether states as a form of government could have existed. States such as the Aztec, Inca or the Mesopotamian and Egyptian civilizations require a bureaucracy and record keeping system to account for the payment of taxation (in goods rather than money) and the distribution of produce to government bureaucrats, soldiers and supporters. If writing did not exist, it would be difficult or impossible to run or control any political entity larger than a chiefdom. Somewhere, as societies got bigger and bigger, writing or a similar record keeping system is needed to control the administration of the government of that society.

Bibliography:

Coulmas Florian (1989) The Writing Systems of the World, Basil Blackwell, Oxford Fischer, Steven Roger (2001) A History of Writing, Reaktion Books, London

Sampson, Geoffrey (1985) Writing Systems, Hutchison, London

Senner, Wayne (ed) (1989) The Origins of Writing, University of Nebraska Press, Lincoln 